ORIGINAL ARTICLE

\title{
Ultrastructural changes in dysferlinopathy support defective membrane repair mechanism
}

\author{
G Cenacchi, M Fanin, L B De Giorgi, C Angelini
}

J Clin Pathol 2005;58:190-195. doi: 10.1136/jcp.2004.018978

See end of article for authors' affiliations

\section{Correspondence to:}

Professor C Angelini, Department of

Neurosciences, University

of Padova, via Giustiniani

5, 35128 Padova, Italy;

corrado.angelini@unipd.it

Accepted for publication 3 August 2004

\begin{abstract}
Background: The dysferlin gene has recently been shown to be involved in limb girdle muscular dystrophy type 2B and its allelic disease, Miyoshi myopathy, both of which are characterised by an active muscle degeneration and regeneration process. Dysferlin is known to play an essential role in skeletal muscle fibre repair, but the process underlying the pathogenetic mechanism of dysferlinopathy is not completely understood.

Aims: To define both specific alterations of muscle fibres and a possible sequential mechanism of myopathy development.

Methods: A histological, immunohistochemical, and ultrastructural analysis of 10 muscle biopsies from patients with molecularly diagnosed dysferlinopathy.

Results: An inflammatory response was seen in most of the muscle biopsies. The immunohistochemical pattern demonstrated active regeneration and inflammation. Non-necrotic fibres showed alterations at different submicroscopic levels, namely: the sarcolemma and basal lamina, subsarcolemmal region, and sarcoplasmic compartment. In the subsarcolemmal region there were prominent aggregations of small vesicles, probably derived from the Golgi apparatus, which consisted of empty, swollen cisternae. In the sarcolemma there were many gaps and microvilli-like projections, whereas the basal lamina was multilayered.

Conclusions: The histopathological, immunohistochemical, and ultrastructural data show that dysferlinopathy is characterised by a very active inflammatory/degenerative process, possibly associated with an inefficient repair and regenerative system. The presence of many crowded vesicles just beneath the sarcolemma provides submicroscopical proof of a defective resealing mechanism, which fails to repair the sarcolemma.
\end{abstract}

$M$ utations in the human dysferlin gene cause limb girdle muscular dystrophy type 2B (LGMD2B) and Miyoshi myopathy (MM). ${ }^{1-3}$ At the onset of disease, the patient shows very few clinical signs; these begin at about 10 years of age with hyperlordosis and muscle weakness. The lower limbs are abducted and externally rotated in the LGMD2B phenotype as a result of hip muscle weakness. In the MM phenotype, there is hyperextension of the lower limbs caused by weakness of the quadriceps and gastrocnemius muscle. There is extensive wasting of the distal posterior muscles of the leg and later of the thigh. ${ }^{1-3}$ Ten years after the onset of the disease, pronounced gait abnormalities are present in both the LGMD2B and the MM phenotype: the foot leaves the ground with a double flexion of the knee and the hip. At this stage upper limb swing is also deficient.

\section{"Dysferlin has a central role in membrane fusion and repair"}

The dysferlin gene product is a membrane associated protein that is a member of a class of homologous proteins called "ferlins". Dysferlin is expressed predominantly in skeletal muscle and localises to the sarcolemma without association with the dystrophin-glycoprotein complex. ${ }^{3}{ }^{4}$ Dysferlin has a central role in membrane fusion and repair. ${ }^{5} 6$ Gene expression profiling in dysferlinopathies using a dedicated muscle microarray showed overexpression of genes involved in myogenesis, intracellular protein trafficking, and proteolysis, probably indicative of an active muscle degeneration and regeneration process. ${ }^{3}$ In dysferlin deficient muscle of both humans and mice, muscle inflammation has been correlated with the upregulation of major histocompatibility complex (MHC) class I antigens at the periphery of fibres. ${ }^{7-9}$ This histopathological picture suggests that both muscle inflammation and complement cascade activation precede the necrosis, and might be triggered by the presence of a structurally altered membrane. ${ }^{4}{ }^{10}$ Previous studies described ultrastructural alterations in dysferlinopathy focusing on plasmalemmal defects, alterations in the basal lamina, and degradation of nearby subsarcolemmal organelles. ${ }^{10}$ However, the mechanism that leads to muscle degeneration has not been elucidated. Therefore, we performed a morphologicalultrastructural analysis of muscle biopsies from 10 patients in whom dyferlinopathy had been previously molecularly diagnosed, to investigate the process underlying the pathogenetic mechanism according to the recent insights into plasmalemma repair. ${ }^{5611}$

\section{MATERIALS AND METHODS}

We examined at the ultrastructural level 10 muscle biopsies obtained from patients in whom dysferlin deficiency had been diagnosed by western blot and gene mutation analysis.

\section{Electron microscopy}

Small muscle specimens were fixed just after surgery in $2.5 \%$ glutaraldehyde in $0.1 \mathrm{M}$ phosphate buffer at $\mathrm{pH}$ 7.2-7.4, and postfixed in $1 \% \mathrm{OsO}_{4}$ in the same buffer. After dehydration in graded ethanol the specimens were embedded in Araldite. Thin sections were stained in uranyl acetate and lead citrate

Abbreviations: LGMD, limb girdle muscular dystrophy; MHC, major histocompatibility class; MM, Miyoshi myopathy 
Table 1 Clinical data and muscle pathological changes

\begin{tabular}{|c|c|c|c|c|c|c|c|c|}
\hline Patient, sex & $\begin{array}{l}\text { Age at } \\
\text { biopsy }\end{array}$ & $\begin{array}{l}\text { Age at } \\
\text { onset }\end{array}$ & $\begin{array}{l}\text { Clinical } \\
\text { diagnosis }\end{array}$ & $\begin{array}{l}\text { Diameter } \\
\text { (range, } \mu \mathrm{m} \text { ) }\end{array}$ & $\begin{array}{l}\text { Fibrofatty } \\
\text { tissue }\end{array}$ & $\begin{array}{l}\text { Lobulated } \\
\text { fibres }\end{array}$ & $\begin{array}{l}\text { Degenerative } \\
\text { fibres }(\%)\end{array}$ & $\begin{array}{l}\text { Pathology severity } \\
\text { score }\end{array}$ \\
\hline $1, M$ & 17 & 26 & $M M$ & $5-72$ & ++ & - & 1.13 & Active \\
\hline $2, F$ & 19 & 19 & MM & $8-96$ & ++ & - & 2.30 & Active \\
\hline $3, M$ & 22 & 17 & $M M$ & 8-88 & + & - & 1.46 & Moderate \\
\hline $4, M$ & 26 & 20 & LGMD/MM & $5-112$ & ++ & + & 0.90 & Active \\
\hline $5, \mathrm{~F}$ & 26 & 25 & MM & $16-80$ & + & - & 1.26 & Moderate \\
\hline $6, F$ & 26 & 28 & LGMD & $10-176$ & +++ & - & 4.0 & Active \\
\hline $7, M$ & 31 & 10 & $M M$ & $16-96$ & ++ & - & 0.17 & Moderate \\
\hline $8, M$ & 34 & 17 & LGMD & $16-96$ & + & - & 1.18 & Active \\
\hline $9, \mathrm{~F}$ & 36 & 20 & MM & $16-72$ & + & - & 0 & Mild \\
\hline $10, F$ & 18 & 18 & LGMD/MM & $5-64$ & + & - & 0.5 & Moderate \\
\hline
\end{tabular}

Ages are given in years.

LGMD, limb girdle muscular dystrophy; MM, Miyoshi myopathy; LGMD/MM, pattern of involvement is common to both phenotypes; -, absent; +, scattered lobulated fibres or mild increase of fibrotic tissue; ++ , moderate increase of fibrotic tissue; +++ , pronounced increase of fibrotic tissue.

and observed in a Philips $410 \mathrm{~T}$ transmission electron microscope.

\section{Muscle pathology}

At the time of diagnosis, open muscle biopsy was obtained after written informed consent from different muscles in the lower or upper limbs. Frozen sections were routinely stained; additional serial sections were used for immunohistochemical labelling and processed separately. The total number of fibres for each section (on average, 1500 fibres) was counted and used to calculate the percentage of fibres immunolabelled with the different antibodies.

The following pathological changes were measured or recorded on routinely stained sections: range of fibre size variability, connective tissue proliferation, fatty replacement, fibre splitting, and the presence of lobulated fibres. The inflammatory response secondary to necrosis (phagocytosis) was identified by the presence of macrophages. The extent of each pathological change was judged by visual inspection of the same observer, and graded as follows: absent or normal $(-)$, slightly increased $(+)$, moderately increased $(++)$, and severely increased $(+++)$.

Muscle fibre degeneration included opaque fibres, hyaline fibres, and those undergoing phagocytosis. Muscle regeneration was expressed as the percentage of fibres showing positive labelling with three antibodies used as markers of regeneration: fetal myosin, laminin $\mathrm{A}$, and vimentin.

The severity of the dystrophic process and muscle histopathology was scored using three different categories. (1) Severe dystrophic process: degenerating and regenerating fibres, pronounced fibrofatty replacement; (2) moderate dystrophic process: a few degenerating fibres, mild fibrosis; and (3) mild myopathic features: myopathic features, central nuclei, split fibres.

\section{Immunohistochemical analysis}

Serial muscle biopsies were sectioned, collected on to gelatine coated slides, air dried, blocked with bovine serum albumin in phosphate buffered saline, and incubated for one hour with the appropriate primary antibodies diluted $1 / 100$. The antibodies used were monoclonal antibodies directed against: caveolin 3 (Transduction Laboratories, Lexington, Kentucky, USA), the Golgi complex (Chemicon, Temecula, California, USA), vimentin (Monosan, Uden, The Netherlands), laminin A (Chemicon), fetal myosin (Novocastra, Newcastle upon Tyne, UK), macrophages (clone EBMll; Dako, Carpinteria, California, USA), CD4 positive helper/inducer T cells (clone MT310; Dako), CD8 positive cytotoxic/suppressor $\mathrm{T}$ cells (clone DK25; Dako), and MHC class I molecules (W6/32; Dako).

After washing, the specific labelling was developed by immunofluorescence, using antimouse cyanine 3 conjugated immunoglobulin (Caltag, Burlingame, California, USA) diluted 1/100 and incubated for 30 minutes. Sections were examined with epifluorescence microscopy; the same optical fields have been identified in serial sections.

\section{RESULTS}

\section{Muscle pathology and immunohistochemistry}

According to the characteristics and severity of the pathological picture, moderate dystrophic and active dystrophic patterns were characterised by increased fibre size variability and fibrofatty replacement; advanced stage dystrophy showed many lobulated fibres (table 1).

Table 2 Immunohistochemical data

\begin{tabular}{|c|c|c|c|c|c|c|c|c|c|c|}
\hline \multirow[b]{2}{*}{ Patient } & \multirow{2}{*}{$\begin{array}{l}\text { Type } 1 \text { fibres } \\
(\%)\end{array}$} & \multirow{2}{*}{$\begin{array}{l}\text { Muscle } \\
\text { type }\end{array}$} & \multicolumn{3}{|c|}{ Regeneration } & \multicolumn{5}{|c|}{ Inflammatory features } \\
\hline & & & FM (\%) & V (\%) & LA (\%) & MHC class I & Macrophages & T4 cells & T8 cells & Exudate localisation \\
\hline $\mathrm{BL}$ & 46.2 & VL & 37.6 & 3.6 & 31.2 & ++ & ++ & + & - & Endomysial \\
\hline BR & 45.4 & VL & 24.6 & 8.5 & 11.9 & ++ & $+H$ & ++ & - & Endomysial \\
\hline GP & 23.8 & $\mathrm{BB}$ & 6.4 & 1.6 & 4.9 & + & ++ & + & - & Perimysial \\
\hline CR & 21.4 & $\mathrm{VL}$ & 14.9 & 2.7 & 22.4 & ++ & + & + & + & Perimysial \\
\hline$C M$ & 22.0 & $D$ & 7.6 & 2.2 & 13.1 & ++ & ++ & + & - & Perimysial \\
\hline PB & 7.3 & G & 55.5 & 19.0 & 21.2 & +++ & +++ & + & + & $\begin{array}{l}\text { Perivascular, } \\
\text { endomysial }\end{array}$ \\
\hline BA & 93.2 & $\mathrm{BB}$ & 1.8 & 0.3 & 2.9 & ++ & + & + & + & $\begin{array}{l}\text { Perivascular, } \\
\text { endomysial }\end{array}$ \\
\hline BA & 42.8 & VL & 14.8 & 1.0 & 14.1 & + & ++ & + & + & Endomysial \\
\hline CC & 47.1 & VL & 0.4 & 0.2 & 0.7 & + & - & - & - & - \\
\hline MG & 40.0 & VL & ND & ND & ND & ND & ND & ND & ND & Perimysial \\
\hline
\end{tabular}

BB, biceps brachii; D, deltoid; FM, fetal myosin; G, gastrocnemius; LA, laminin A; MHC, major histocompatibility complex; ND, not determined; V, vimentin; VL, vastus lateralis; -, absent; +, mild increase of reaction; ++, moderate increase of reaction; +++, pronounced increase of reaction. 


\begin{tabular}{|c|c|c|c|c|c|c|c|c|c|c|}
\hline \multicolumn{6}{|c|}{ Sarcolemma and subsarcolemmal region } & \multicolumn{5}{|c|}{ Sarcoplasmic region } \\
\hline Patient & $\begin{array}{l}\text { Inflam- } \\
\text { mation }\end{array}$ & $\begin{array}{l}\text { Basal } \\
\text { lamina }\end{array}$ & $\begin{array}{l}\text { Microvilli } \\
\text { pseudop }\end{array}$ & $\begin{array}{l}\text { Amorphous } \\
\text { material }\end{array}$ & Vesicles & $\begin{array}{l}\text { Myofibril } \\
\text { lysis }\end{array}$ & $\begin{array}{l}\text { Central } \\
\text { nuclei }\end{array}$ & Mitochondria & Lipids & Stroma \\
\hline$B L$ & - & H & + & ++ & ++ & ++ & + & - & + & + \\
\hline BR & - & + & - & ++ & - & - & - & - & - & - \\
\hline GP & + & + & - & - & - & + & - & + & - & - \\
\hline$C R$ & ++ & + & + & - & ++ & ++ & + & - & - & + \\
\hline$C M$ & ++ & + & + & ++ & ++ & + & + & - & + & - \\
\hline PB & + & + & + & - & ++ & ++ & + & - & + & + \\
\hline BA & + & - & - & + & - & - & \pm & - & + & - \\
\hline $\mathrm{BA}$ & + & - & + & + & \pm & \pm & + & + & - & - \\
\hline CC & - & - & - & ++ & - & - & + & + & - & - \\
\hline MG & + & + & - & - & - & \pm & - & + & - & - \\
\hline
\end{tabular}

We found the highest rates of degeneration $(>1 \%$ of total fibres) and regeneration ( $>10 \%$ of total fibres) in muscle biopsies showing active dystrophy (tables 2, 3), mostly from young patients.

An increased inflammatory response (moderate or pronounced increase in MHC class I and/or macrophage reaction) was seen in most of the muscle biopsies $(67 \%)$, and it was present in almost all cases with active dystrophy (tables 1, 2). We found that macrophages were the most abundant inflammatory cell type, and they were seen surrounding or invading muscle fibres or localised to the endomysium. T cells were localised both in the perimysium and in the perivascular region, and in the endomysium or invading fibres in phagocytosis. An increased MHC class I positive reaction was seen in association with the presence of macrophages (table 2), but was also localised in regenerating fibres, and occasionally on the surface of non-necrotic and non-regenerating fibres.

The study of serial muscle sections immunolabelled with antibodies to caveolin 3, the Golgi, and fetal myosin showed different pathological patterns: one was characterised by basophilic (fig 1A) and fetal myosin positive fibres (fig 1D), which showed reduced caveolin 3 labelling (fig IC) and were almost negative for Golgi antibody (fig 1B); other atrophic non-regenerating fibres showed increased labelling for caveolin 3, possibly related to the thickening of the sarcolemma.

\section{Muscle ultrastructure \\ Inflammatory response}

An inflammatory response was seen in most of the muscle biopsies. It was characterised by $\mathrm{T}$ cells localised in the perimysium, in the perivascular region, and in the endomysium or invading fibres in phagocytosis. Non-necrotic fibres were selected for the subsequent study at the ultrastructural level.

Muscle cell alterations (table 3 ) could be easily divided into three groups according to their localisation: (1) sarcolemma and basal lamina; (2) subsarcolemmal region; and (3) sarcoplasmic compartment.

(1) Sarcolemma and basal lamina. The ultrastructural study of the surface cell layer showed few sarcolemmal gaps and many elongated microvilli-like projections (fig 2A), which were oriented either parallel (fig $2 \mathrm{~B}$ ) or perpendicular to the sarcolemma. The basal lamina was usually
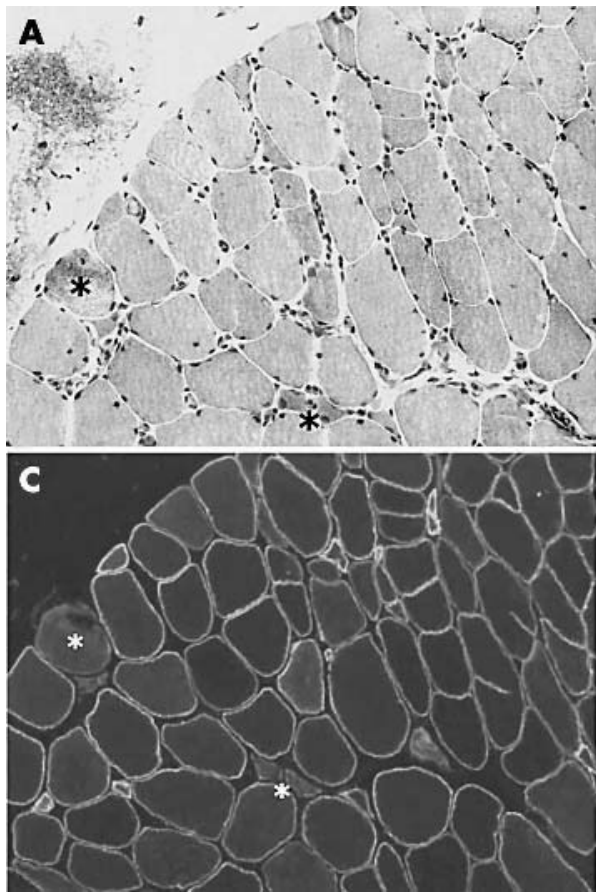
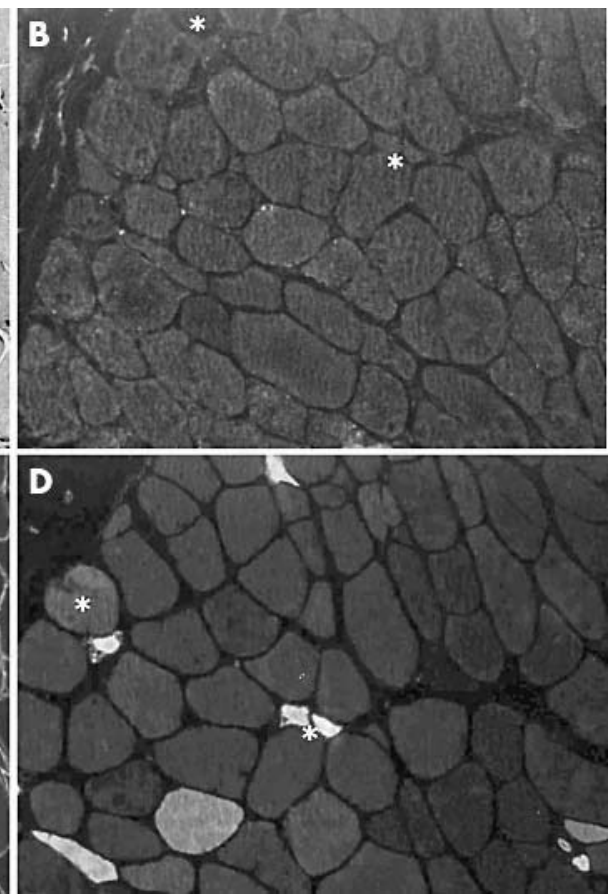

Figure 1 Skeletal muscle morphology and immunohistochemistry in dysferlinopathy. A set of serial muscle biopsy sections (patient CR) shows muscle morphology and

immunolabelling with different antibodies. (A) Haematoxylin and eosin (H\&E) staining. Immunostaining with antibodies to (B) the Golgi zone, (C) caveolin 3, and (D) fetal myosin. The asterisks indicate the same fibres in different serial sections. Two basophilic muscle fibres (A) are positive for fetal myosin (D) and show greatly reduced caveolin 3 labelling (C) and an absence of Golgi labelling (B). Additional atrophic fibres are negative for fetal myosin and the Golgi zone, but they are strongly positive for caveolin 3 . Original magnification, $\times 200$. 
thickened or multilayered (fig 2B), and seemed to include some globular aggregates of amorphous electrondense material (fig 2C). These globules were also seen tightly associated with microvilli-like projections. Occasional lymphocytes were seen inside the virtual space between the sarcolemma and the basal lamina (fig 2D).

(2) Subsarcolemmal region. This region was characterised by the presence of several aggregates of small vesicles (fig 3A), which probably derive from the Golgi apparatus (fig 3B). The Golgi apparatus was often made up of swollen, empty cisternae close to the periphery of the nucleus. Some non-specific degenerative alterations (fig 3D) could also be seen, together with large vacuoles containing myelin-like lamellae (fig 3C).

(3) Sarcoplasmic compartment. The main submicroscopic alterations were non-specific architectural changes, mild or severe loss of myofilaments, dilated rough endoplasmic reticulum and $\mathrm{T}$ system profiles, and degenerative changes of the mitochondria. Some central nuclei were also seen, in addition to many lipid vacuoles and mitochondrial aggregates, both in the intermyofibrillar and subsarcolemmal regions.

\section{DISCUSSION}

The diagnosis of dysferlinopathy in our 10 patients was based on the detection of dysferlin deficiency on muscle biopsy and was confirmed by the identification of dysferlin gene mutations in nine of the 10 cases.

To date, only a few studies have reported on the ultrastructural alterations seen in patients with dysferlinopathy, and they have suggested abnormalities of the sarcoplasmic compartment ${ }^{12}$ and demonstrated microvilli projection, subsarcolemmal vesicles, and small plasmalemmal defects. ${ }^{10}$

The membrane attack complex was also found to be increased in some patients ${ }^{10}$ and extensive inflammatory infiltrates were observed. ${ }^{7}$ Using immunohistochemistry, we found increased expression of MHC class I and increased numbers of macrophages and $\mathrm{T}$ lymphocytes in most patients; ultrastructural studies showed that some macrophages and lymphocytes were tightly adhered to the sarcolemma.
Recently, it has been suggested that dysferlinopathy results from abnormal plasma membrane repair mechanisms. ${ }^{5611}$ Our results show that the sarcolemma and basal lamina are unusually thickened and multilayered. We found many plasmalemmal gaps, microvilli-like projection, and aggregates of amorphous electrondense material. In the subsarcolemmal region there were prominent aggregates of small vesicles, which probably derived from the Golgi apparatus, and were composed of empty, swollen cisternae.

The patients who received a histopatological score graded as moderate or severe showed alterations at both the sarcolemmal and sarcoplasmic level. The importance of the presence of elongated microvilli-like projections, oriented parallel to the cell surface, is still unclear: they are probably a consequence of sarcolemmal damage, or they could be an attempt to extrude membrane segments that have been abnormally assembled.

The plasmalemma resealing mechanism seems very important both in normal and in pathological conditions. ${ }^{6}{ }^{12}$ Membrane disruptions mostly occur after eccentric contractions and various degrees of mechanical stress; a defective membrane repair mechanism easily results in the necrosis of muscle fibres. The repairing capacity of plasmalemma is dependent on the extracellular presence of $\mathrm{Ca}^{++}$with a "surface precipitation reaction" or exocytotic delivery of internal membrane. ${ }^{13}$

The role of exocytosis is probably most important for relatively large $(>1 \mu \mathrm{m}$ in diameter $)$ disruptions. ${ }^{13}$ The mechanism by which intracellular vesicles successfully repair plasmalemma damage is the formation of a "patch" of internally derived membrane over a disruption site. Membrane resealing is triggered by $\mathrm{Ca}^{++}$entry through the membrane gap; this causes a rapid fusion of vesicles in the subsarcolemmal region, which can occur homotypically (vesicles fusing with each other) or heterotypically (vesicles fusing with the sarcolemma itself). ${ }^{13}$

The role of dysferlin, which harbours cytoplasmic $\mathrm{Ca}^{++}$ binding domains, would be to trigger signal transduction events, such as phospholipid binding and vesicle fusion. ${ }^{6}{ }^{13} 14$ The presence of many crowded vesicles just beneath the sarcolemma provides submicroscopical proof of a defective resealing mechanism, which fails to repair the sarcolemma. These findings agree with those reported in dysferlin null
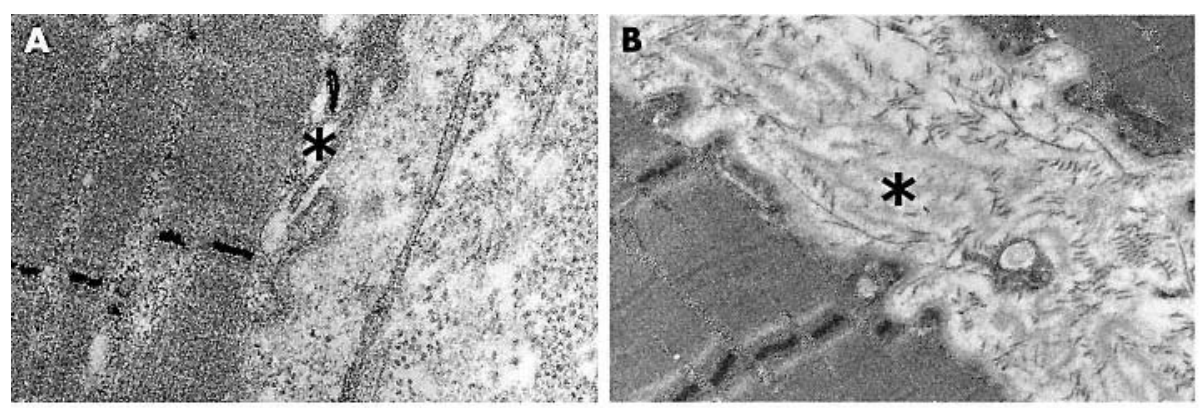

Figure 2 Electron microscopy of skeletal muscle from a patient with dysferlinopathy. (A) Elongated microvilli-like projections oriented parallel to the cell surface and close to sarcolemmal gap (asterisk); (B) basal lamina reduplication (asterisk); (C) many electrondense globular aggregates (asterisk); (D) a lymphocyte localised in the virtual space between the sarcolemma and the basal lamina. Original magnification, $\times 9100$.
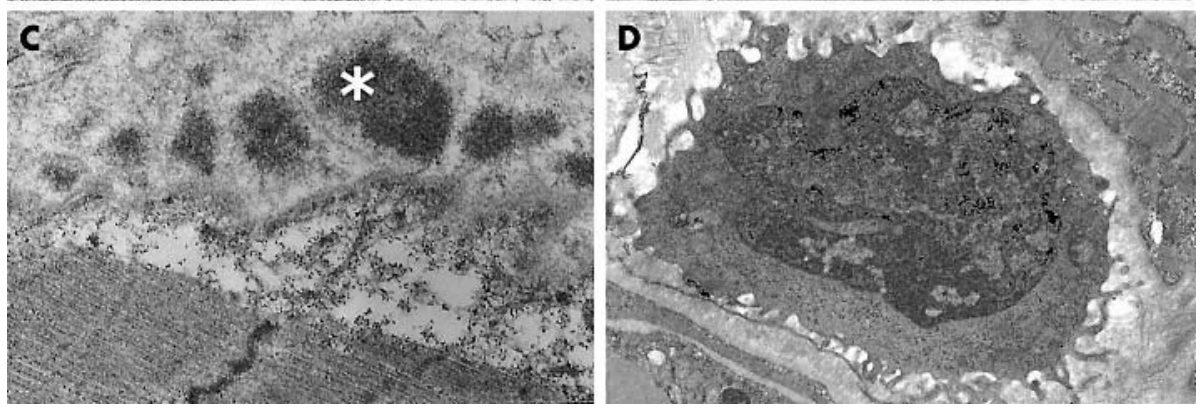

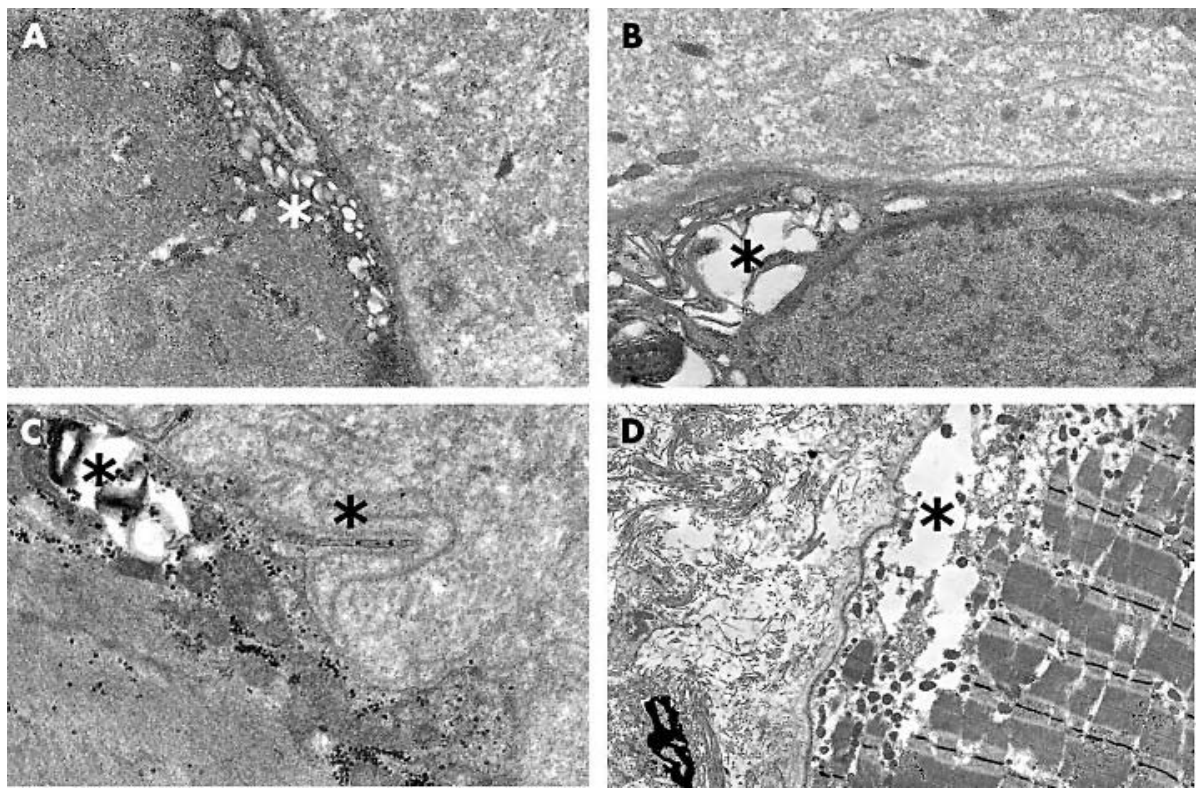

Figure 3 Electron microscopy of skeletal muscle from a patient with dysferlinopathy. (A) Subsarcolemmal accumulation of vesicles (asterisk) derived from the Golgi apparatus with swollen cisternae seen in (B) (asterisk) (C) vacuoles (asterisk on the left) with degenerating myelin figures and microvilli-like projections (asterisk on the right); (D) severe loss of myofilaments, dilated rough endoplasmic reticulum, and nonspecific degenerative changes of mitochondria; large subsarcolemmal vacuoles with loss of microfilaments are also seen (asterisk). Original magnification, $\times 9100(\mathrm{~A}-\mathrm{C})$ and $\times 5600$ (D). mouse muscle, where accumulation of vesicles beneath a damaged membrane was observed. ${ }^{5}$ Recent work has established that the vesicle population used for patch formation probably derives from lysosomes. ${ }^{13}$ We saw several Golgi zones composed of many enlarged, swollen cisternae and tubules. These structures were sometimes associated with large vacuoles, mostly empty or containing myelinated figures.

\section{"Although degenerative sarcoplasmic compartment abnormalities can be seen in various muscular dystro- phies, sarcolemmal and basal lamina changes appear to be more specific to dysferlinopathy"}

Similar, abnormally large, vacuolated structures in the subsarcolemmal area have been described in the caveolin deficient muscle fibres of LGMDIC..$^{15}$ The presence of similar large vacuoles in the subsarcolemmal region in our cases could explain the interaction of dysferlin with caveolin 3 in human skeletal muscle, because muscle caveolae are thought to play a role in the formation or organisation of the $\mathrm{T}$ tubule system. ${ }^{15-17}$

In dystrophinopathies and sarcoglycanopathies, the lack of one component of the dystrophin-glycoprotein complex at the sarcolemma causes the disruption of the structural linkage between the cytoskeleton and the extracellular matrix, with consequent instability of the sarcolemma. ${ }^{5}$ However, a different mechanism is at work in dysferlinopathy. ${ }^{511}$ Although degenerative sarcoplasmic compartment abnormalities-including the loss of myofilaments, dilated rough endoplasmic reticulum, and abnormal T tubules-can be seen in various muscular dystrophies, sarcolemmal and basal lamina changes appear to be more specific to dysferlinopathy. Sites with disrupted sarcolemma and vesicle accumulation can be detected only in dysferlin null muscle.

Similar to previous observations in human muscle, ${ }^{10}{ }^{12}$ the results of our study suggest a sequential pathogenetic mechanism for the development of fibre damage in dysferlinopathy. The histopathological and ultrastructural changes that we observed could be collected under the following sequential physiopathological steps: (1) sarcolemmal lesion in small gaps; (2) accumulation of vesicles probably derived from the Golgi; (3) formation of papillary projections, pluristratification of basal lamina, and electron dense material during abnormal repair mechanisms; (4) inflammation and regeneration; and (5) degeneration, as demonstrated by vacuoles with degenerating myofibrils, severe loss of myofilaments, dilated rough endoplasmic reticulum, and changes in the mitochondria. Although inflammation and degeneration are prominent in early dysferlinopathy, both plasmalemma resealing and repair are not efficient.

Our results differ from earlier studies in dysferlin null mice, ${ }^{5}$ because we found pluristratification of the basal lamina, papillary projections, electron dense globular aggregates, and inflammatory features such as lymphocytes in the virtual space between the sarcolemma and the basal lamina. However, in another animal model (AJ mice and dysferlin gene transgenic mice) there was pronounced thickening and focal duplication of the basal lamina. ${ }^{18}$ Also in this model, accumulation of vesicles beneath the sarcolemma and areas of membrane discontinuity were seen. ${ }^{18}$ Myofibre degeneration in dysferlin null muscle appears to be remarkably similar between different species.

Our present study provides novel insights into the pathogenesis of the disease, which largely support the theory of an abnormal plasma repair mechanism. Unfortunately, in humans, a direct functional analysis cannot be done; therefore, some caution is recommended with regard to these conclusions.

\section{Take home messages}

- We undertook a histological, immunohistochemical, and ultrastructural analysis of 10 muscle biopsies from patients with molecularly diagnosed dysferlinopathy

- Dysferlinopathy was characterised by a very active inflammatory/degenerative process, possibly associated with an inefficient repair and regenerative system

- The presence of many crowded vesicles just beneath the sarcolemma provides submicroscopical proof of a defective resealing mechanism, which fails to repair the sarcolemma 
Ultrastructural aggregations of small vesicles are seen both in human and mouse dysferlin deficient muscle; however, human dystrophy presents additional features such as papillary projections and extrusion of electron dense globular material that are probably caused by a defective resealing and regeneration mechanism. Ultrastructural analysis showed that pronounced thickening of the basal lamina and isolated areas of membrane discontinuity appear to be the early stages of loss of sarcolemma integrity and a characteristic feature of dysferlinopathy.

\section{ACKNOWLEDGEMENTS}

This study was supported by grants from Telethon-Italy (numbers GTF02009 and 1321).

\section{Authors' affiliations}

G Cenacchi, L B De Giorgi, Clinical Department of Radiological and Histocytopathological Sciences, University of Bologna, 40138 Bologna, Italy

M Fanin, C Angelini, Neuroscience Department, University of Padova, and Venetian Institute of Molecular Medicine, 35128 Padova, Italy

\section{REFERENCES}

1 Zatz M, de Paula F, Starling A, et al. The 10 autosomal recessive limb-girdle muscular dystrophies. Neuromuscul Disord 2003;13:532-44.

2 Laval SH, Bushby KM. Limb-girdle muscular dystrophies-from genetics to molecular pathology. Neuropathol Appl Neurobiol 2004;30:91-105.

3 Campanaro S, Romualdi C, Fanin M, et al. Gene expression profiling in dysferlinopathies using a dedicated muscle microarray. Hum Mol Genet 2002;11:3283-98.
4 Fanin M, Angelini C. Muscle pathology in dysferlin deficiency. Neuropathol Appl Neurobiol 2002;28:461-70.

5 Bansal D, Miyake K, Vogel SS, et al. Defective membrane repair in dysferlindeficient muscular dystrophy. Nature 2003;423:168-72.

6 Doherty KR, McNally EM. Repairing the tears: dysferlin in muscle membrane repair. Trends Mol Med 2003:9:327-30.

7 Gallardo E, Rojas-Garcia R, de Luna N, et al. Inflammation in dysferlin myopathy: immunohistochemical characterization of 13 patients. Neurology 2001;57:2136-8.

8 Confalonieri P, Oliva L, Andreetta F, et al. Muscle inflammation and MHC class I up-regulation in muscular dystrophy with lack of dysferlin: an immunopathological study. J Neuroimmunol 2003;142:130-6.

9 Kostek CA, Dominov JA, Miller JB. Up-regulation of MHC class I expression accompanies but is not required for spontaneous myopathy in dysferlindeficient SJL/J mice. Am J Pathol 2002;160:833-9.

10 Selcen D, Stilling G, Engel AG. The earliest pathologic alterations in dysferlinopathy. Neurology 2001;56:1472-81.

11 Hayashi YK. Membrane-repair machinery and muscular dystrophy. Lancet 2003:362:843-4.

12 Piccolo F, Moore SA, Ford GC, et al. Intracellular accumulation and reduced sarcolemmal expression of dysferlin in limb-girdle muscular dystrophies. Ann Neurol 2000;48:902-12.

13 McNeil PL. Repairing a torn cell surface: make way, lysosomes to the rescue. J Cell Sci 2002;115:873-9.

14 Lennon NJ, Kho A, Bacskai BJ, et al. Dysferlin interacts with annexins $A 1$ and $\mathrm{A} 2$ and mediates sarcolemmal wound-healing. J Biol Chem 2003;278:50466-73.

15 Minetti $C$, Bado M, Broda $P$, et al. Impairment of caveolae formation and Tsystem disorganization in human muscular dystrophy with caveolin-3 deficiency. Am J Pathol 2002;160:265-70.

16 Matsuda C, Hayashi YK, Ogawa M, et al. The sarcolemmal proteins dysferlin and caveolin-3 interact in skeletal muscle. Hum Mol Genet 2001;10:1761-6.

17 Capanni C Sabatelli P, Mattioli E, et al. Dysferlin in a hyperCKaemic patient with caveolin 3 mutation and in $\mathrm{C} 2 \mathrm{C} 12$ cells after p38 MAP kinase inhibition. Exp Mol Med 2003;35:538-44.

18 Ho M, Post CM, Donahue LR, et al. Disruption of muscle membrane and phenotype divergence in two novel mouse models of dysferlin-deficiency. Hum Mol Genet 2004;13:1999-2010. 